Published in final edited form as:

Thromb Haemost. 2007 May ; 97(5): 755-762.

\title{
Chemokines as mediators of angiogenesis
}

\author{
Borna Mehrad $^{1}$, Michael P. Keane ${ }^{2}$, and Robert M. Strieter ${ }^{1}$ \\ ${ }^{1}$ Division of Pulmonary and Critical Care Medicine, University of Virginia, Charlottesville, Virginia, \\ USA \\ ${ }^{2}$ Division of Pulmonary and Critical Care Medicine, David Geffen School of Medicine at University \\ of California, Los Angeles, California, USA
}

\section{Summary}

Chemokines were originally described as cytokines that mediate leukocyte recruitment to sites of inflammation. Members of a subgroup of chemokines, the CXC family, also play a critical role in both physiologic and pathologic angiogenesis, including in the context of chronic inflammation, fibrosis, and malignancy. A unique feature of this family of cytokines is that, on the basis of their structure and receptor binding, individual ligands display either angiogenic or angiostatic biological activity in the regulation of angiogenesis. In this review, we summarize the key literature in this growing field.

\section{Keywords}

Chemokine; chemokine receptor; angiogenesis; cancer

\section{Introduction}

Chemokines are a superfamily of homologous $8-10 \mathrm{kDa}$ heparin-binding proteins, originally described for their role in mediating leukocyte recruitment to sites of inflammation. A subgroup of chemokines, the CXC family, plays a critical role in angiogenesis, in both physiologic and pathologic contexts, including chronic inflammation, fibrosis, and malignancy.

Structurally, the defining feature of the CXC chemokine family is four conserved cysteine aminoacid residues near the amino-terminus, the first two of which are separated by a nonconserved aminoacid, thus constituting the Cys-X-Cys or ' $\mathrm{CXC}$ ' motif. This family is further subdivided on the basis of the presence or absence of another three aminoacid sequence, glutamic acid-leucine-argenine (the 'ELR' motif), immediately proximal to the $\mathrm{CXC}$ sequence. Unique amongst the mediators of angiogenesis, this structural motif determines the function of specific ligands: the ELR containing CXC chemokines, originally discovered for their potent neutrophil chemoattractant properties, promote angiogenesis, while the non-ELR ligands, which attract mononuclear leukocytes, inhibit angiogenesis (Table 1; references $[1,2]$ ). 


\section{CXCR2: The major angiogenic chemokine receptor}

The human ELR+ CXC chemokine ligands signal via one of two receptors, CXCR1 and CXCR2, whereas there is no mouse equivalent for CXCR1, and all murine ELR+ CXC chemokines signal via CXCR2. Several lines of data indicate that the angiogenic properties of ELR+ CXC chemokines are only mediated via CXCR2 in the human, as well as the murine system: First, while only CXCL8 and CXCL6 specifically bind to CXCR1, all human ELR+ CXC chemokines mediate angiogenesis. Second, while both CXCR1 and CXCR2 are detected in endothelial cells (3-5), only the expression of CXCR2 is necessary for endothelial cell chemotaxis $(3,4)$. In addition, the response of human endothelial cells to CXCL8 can be blocked by immunoneutralization of CXCR2 or inhibitors of its intracellular signalling pathways (6).

The in-vivo role of CXCR2 in mediating ELR+ CXC chemokine- induced angiogenesis has been examined in models of corneal neovascularization (3) and wound repair (7). In the corneal system, both CXCR2-deficient hosts and immunoneutralization of CXCR2 inhibited corneal vascularization in response to ELR+ CXC chemokine ligands (3). In the wound healing model, full-thickness excisional wounds demonstrated delayed healing which was associated with impaired angiogenesis in CXCR2-deficient mice (7).

\section{CXCR3: The major chemokine receptor inhibiting angiogenesis}

The receptor for non-ELR CXC chemokines that mediate angiostasis is CXCR3 (8-12). Endothelial cells express CXCR3 (13), and CXCR3 ligands inhibit microvascular human endothelial cell migration and proliferation in response to a variety of angiogenic factors (5, 14). CXCR3 biology is complicated by the fact that the receptor exists as at least three distinct splice variants: CXCR3A, CXCR3B, and CXCR3-alt. CXCR3A mediates the CXCR3 ligand-dependent chemotactic activity of mononuclear cells, whereas CXCR3B mediates the angiostatic activity of CXCL4, CXCL9, CXCL10, and CXCL11 on human microvascular endothelial cells (15). This supports the notion that if CXCR3 ligands can be spatially expressed within the tumour, then CXCR3B activation can inhibit tumourassociated angiogenesis (15). CXCR3-alt, which is generated by post-transcriptional exon skipping, retains signalling activity to CXCL11 but a much reduced response to CXCL9 or CXCL10 (9). The specific contribution of CXCR3-alt to angiogenesis remains to be elucidated. Similarly, CXCR7 has recently been recognized as a novel receptor for both CXCL11 and CXCL12 $(16,17)$. While this receptor has been implicated in tumour survival and growth in vivo, its specific function in angiogenesis has not been fully elucidated.

Since CXCL10 contains binding domains for both CXCR3 and glycosaminoglycans, the specificity of CXCL10-CXCR3 interaction in mediating angiostasis has been examined by transfecting CXCL10 variants that cannot bind CXCR3 or glycosaminoglycans into a melanoma cell line (18). This work has shown that, at least in the context of this model system, tumour growth and tumour-associated angiogenesis are specifically dependent on interaction of CXCL10 with CXCR3 but not glycosaminoglycans.

\section{CXCR4: A role in angiogenesis?}

The CXCL12-CXCR4 ligand-receptor pair has been implicated in migration of cancer cells to induce metastases (19) and also in promoting angiogenesis $(5,20-22)$, but distinguishing between the contributions of these mechanisms in the context of disease has been difficult. Expression of CXCR4 has been documented in multiple tumour lines and primary cancer cells, whereas the ligand, CXCL12, is essentially absent from the tumours $(19,23,24)$. Absence of CXCL12 from tumours could hypothetically be explained by the tumour cells "out-competing" endothelial cells for available ligand. In animal models bearing breast or non-small cell lung cancers (NSCLC), immunoneutralization of CXCL12 or CXCR4 did not 
affect the size or angiogenesis of the primary tumour but attenuated tumour metastases (19, 23), suggesting that, at least in these systems, the CXCL12-CXCR4 axis mediates metastases independent of angiogenesis. In contrast, similar depletion of classical angiogenic factors and their receptors results in measurable reduction of angiogenesis, and a consequent reduction in both primary tumour size and metastases $(1,25-27)$.

\section{CC chemokines}

While most of the literature on chemokine regulation of angiogenesis has centered on the role of the CXC family, several members of the CC chemokine family, including CCL11, CCL16 and CCL21 have also been implicated in angiogenesis (28-30). The best studied CC chemokine ligand implicated in angiogenesis, however, is CCL2: endothelial cells express the CCL2 receptor, CCR2, and demonstrate chemotaxis and tube formation in reponse to CCL2 in vitro $(31,32)$. In vivo, CCL2-mediated angiogenesis has been demonstrated in corneal implantation, chick chorioallantoic membrane, Matrigel plug, and sponge implantation models (33-35), and appears to be independent of its induction of leukocyte recruitment (34). The chemotaxis of endothelial cells by CCL2 is dependent on CCL2induced over-expression of membrane type 1-metalloproteinase on endothelial cell surfaces (31) and is mediated via the ERK cascade and the transcription factor Ets-1 (36).

\section{Virally encoded chemokine receptors}

Human herpes virus-8 (HHV-8, also known as Kaposi sarcoma herpes virus, KSVH), is the cause of human Kaposi's sarcoma and body-cavity lymphoma, and encodes a seventransmembrane G-protein coupled receptor that is homologous to CXCR2 $(37,38)$. This receptor is constitutively signal-coupled, but its signal-coupling can be further augmented when bound to ELR+ chemokine ligands, CXCL8 or CXCL1 (39-41). The relevance of this receptor to pathogenesis of Kaposi's sarcoma was established using transgenic mice expressing KSHV-GPCR, which spontaneously develop angioproliferative KS-like lesions $(42,43)$. In further support of this contention is the finding that a point mutation of CXCR2, but not CXCR1, results in constitutive signalling of the receptor and cellular transformation of transfected cells in a similar manner as KSHV-GPCR (37). Furthermore, the persistent activation of CXCR2 by specific CXC chemokine ligands can lead to a similar cellular transformation as seen with either the point mutation of CXCR2 or KSHVGPCR (37).

Another virally encoded chemokine receptor, US28, is expressed by human cytomegalovirus and also induces a pro-angiogenic phenotype (44). US28 expressing cells promote tumourigenesis and angiogenesis in mice (44). This is mediated through the expression of VEGF, indicating important interactions between chemokines/chemokine receptors and VEGF in promoting tumour growth. Furthermore these findings indicate potential mechanisms for viral involvement in the tumourigenesis and angiogenesis.

\section{Duffy antigen}

The red blood cell Duffy antigen receptor for chemokines (DARC) is a promiscuous but non-signalling chemokine receptor (45). Within the ELR+ CXC chemokines, DARC binds the angiogenic ELR+ CXC chemokines CXCL1, CXCL5 and CXCL8. Transgenic expression of the Duffy antigen on mouse endothelial cells resulted in impaired angiogenic response of the animals to ELR+ CXC chemokines in vivo (46). Conversely, in a mouse model of spontaneous prostate cancer, animals on a DARC-deficient background developed larger and more aggressive tumours (47). This was associated with increased intra-tumour levels of angiogenic ELR+ CXC chemokines and blood vessel density, supporting the hypothesis that red blood cell expression of DARC sequesters angiogenic chemokines thereby inhibiting tumour growth. 
To assess its therapeutic potential, DARC was stably transfected and over-expressed in a human NSCLC tumour cell line. This did not affect the growth characteristics of the tumour in vitro, but when implanted into animals, DARC-expressing tumours had greater necrosis and decreased tumour cellularity, associated with a marked decrease in tumour-associated vasculature and a reduction in metastatic potential (45). Similar findings have also been reported using breast cancer cell lines (48). In summary, DARC appears to act as a decoy receptor that inhibits angiogenesis by sequestering ELR+ CXC chemokines.

\section{Chemokine-mediated inhibition of angiogenesis via undefined receptors}

CXCL4, a component of the platelet a-granule, was the first chemokine described to inhibit neovascularization (49). In addition to signalling via CXCR3B, discussed earlier, CXCL4 has been postulated to mediate inhibition of angiogenesis by either interaction with cell surface glycosaminoglycans or via direct interaction with proangiogenic mediators and their receptors (50). CXCL4 is reported to prevent activation of the extracellular signal- regulated kinase by bFGF, and to inhibit down-regulation of the cyclin-dependent kinase inhibitor p21 $(51,52)$. Furthermore, CXCL4 function is not abrogated in heparan sulfate-deficient cells, and CXCL4 mutants or peptides lacking heparin-affinity are capable of inhibiting angiogenesis $(50,53,54)$, suggesting that interaction with cell surface glycosaminoglycans is not essential for these effects. Other studies have reported that the inhibitory effect of CXCL4 is mediated through complex formation with bFGF or CXCL8 $(53,55)$. Finally, CXCL4 also exists as a non-allelic gene variant, CXCL4L1, which differs from CXCL4 in its signalling region, subcellular localization, and regulation of secretion (56-58). CXCL4L1 has been found to be a more potent inhibitor of angiogenesis both in in-vitro and in in-vivo models of angiogenesis (59), but the mechanism by which this variant mediates these effects is yet to be defined.

CXCL14, another ELR-negative CXC chemokine, is another recently identified inhibitor of angiogenesis. CXCL14 was first identified by differential display of normal oral epithelial cells and head and neck squamous cell carcinoma when it was noted to be down-regulated in tumour specimens (60-62), but its mechanism of action, including its receptor, remain to be identified. CXCL14 was found to inhibit microvascular endothelial cell chemotaxis to CXCL8, bFGF, and VEGF in vitro and attenuate angiogenesis to these agonists in vivo (63). In the context of the prostate, CXCL14 expression did not differ between normal tissue and hypertrophic tissue but it correlated with Gleason score in prostate cancer, and inhibited tumour growth when transfected into prostate cancer cells implanted into animals (64). The above studies support the notion that the loss or inadequate expression of CXCL14 is associated with the transformation of normal epithelial cells to cancer and the promotion of a pro-angiogenic microenvironment suitable for tumour growth. The receptor that mediates the actions of CXCL14 remains to be determined.

\section{Chemokine-induced angiogenesis in inflammatory and fibroproliferative disorders}

Angiogenesis is a demonstrable histopathologic feature of many chronic inflammatory and fibroproliferative disorders, and disproportionate expression of angiogenic CXC chemokines can be demonstrated in many such illnesses; examples include rheumatoid arthritis synovium (65), and psoriatic dermal plaques (66).

Increasing evidence points to a role for inflammation and fibroproliferation in the pathogenesis of atherosclerosis (67-69). Angiogenesis has also been demonstrated within atherosclerotic plaques, and may contribute to the pathogenesis of plaque formation (70-72). The angiogenic ELR+ CXC chemokine, CXCL8, is over-expressed in human coronary 
artery plaque samples, as compared to control samples from internal mammary arteries without atherosclerosis, where it co-localized with factor VIII-related antigen expression on endothelial cells in the coronary atherectomy specimens, and is the major mediator of net angiogenic activity of the plaque in the rat cornea micro-pocket assay (73). A large number of chemokines are induced in the context of myocardial ischaemia and heart failure $(74,75)$, but the specific contribution of these mediators to angiogenesis has not been clearly established. CCL2, in particular, was critically involved in infarct-associated inflammation and subsequent healing in a mouse model of myocardial infarction, but its absence did not influence angiogenesis (76). CCL2 has, however, been implicated in ischaemia-induced arteriogenesis in a murine hind-limb ischaemia model (77), and may therefore be relevant in similar collateralization in the context of chronically ischaemic myocardium.

Angiogenesis is also a major mechanism in the pathogenesis of a number of lung diseases. The human lung is supplied by both the pulmonary and the bronchial circulation.

Neovascularization and development of anastamoses between these circuits control pulmonary vascular resistance, necessary to maintaining blood flow to the metabolically active lung tissue in the context of injury and repair (78-81). Compensatory neovascularization of up to $30 \%$ of the original pulmonary blood flow can occur in the bronchial circulation in all mammals in response to marked increases in pulmonary vascular resistance (81), and the mouse systemic circulation can supply $15 \%$ of the pulmonary flow within days after pulmonary artery ligation, a process that is associated with up-regulation of ELR+ CXC chemokines but not VEGF $(82,83)$.

Idiopathic pulmonary fibrosis (IPF) is a chronic and often fatal pulmonary fibroproliferative lung disease characterized by on-going and dysregulated tissue repair. Neovascularization was first recognized in the IPF lung in postmortem studies, as extensive anastamoses between pulmonary and bronchial circulations (84), and was subsequently identified in animal models of bleomycin-induced pulmonary fibrosis (85). Indeed the lung tissue and bronchoalveolar lavage fluid (BALF) from patients with IPF is strongly angiogenic, as determined in the rat corneal micro-pocket model, and this angiogenic activity is entirely attributable to over-expression of the angiogenic ELR+ CXC chemokine, CXCL8, as compared to angiostatic non-ELR CXC chemokine, CXCL10, in the lung (86). In the mouse model of bleomycin-induced pulmonary fibrosis, the expression and biological activity of angiogenic ELR+ CXC chemokine, MIP-2 (CXCL2/3) contributed to pulmonary fibrosis and angiogenic activity, while CXCL10 had the reverse effect $(87,88)$. Moreover, depletion of endogenous CXCL2/3 or administration of exogenous CXCL10 resulted in marked attenuation of pulmonary fibrosis that was entirely attributable to a reduction in angiogenesis in the lung $(87,88)$. Finally, administration of exogenous CXCL11 in this model also resulted in reduced lung fibrosis, as measured by lung collagen deposition, and this effect was abrogated with concomitant blockade of CXCR3 (89).

Bronchiolitis obliterans syndrome (BOS) is a pulmonary fibroproliferative disorder centered around small airways, and constitutes the single most important cause of long-term organ dysfunction and death in lung transplant recipients (90). Human lung samples from patients with BOS demonstrate aberrant blood vessel formation, and both lung samples and BALF have elevated ELR+ CXC chemokine ligand levels and pronounced angiogenic activity in the corneal micro-pocket model that is inhibited by neutralizing CXCR2 (91). A mouse model of heterotropic tracheal allograft transplantation into MHC-mismatched recipients also demonstrated these properties, which were dependent on CXCR2 and CXCR2 ligands, but were independent of neutrophil presence (91).

Acute respiratory distress syndrome (ARDS) is a common and severe manifestation of acute lung injury, and progresses to a fibroproliferative phase after several days, which is 
associated with marked angiogenesis related to ELR+ CXC chemokines (92): BALF from patients with ARDS has elevated levels of angiogenic chemokines and reduced levels of angiostatic chemokines, as compared to control ventilated patients without ARDS, and this was associated with BALF angiogenic activity and BALF pro-collagen I and pro-collagen III levels (92). In contrast, while BALF levels of VEGF were elevated in ARDS patients, VEGF did not appear to be a predominant factor in contributing to the overall angiogenic activity (92). Taken together, these findings support the notion that angiogenesis is critical to promote fibroplasia and deposition of ECM associated with chronic fibroproliferation, and that angiogenic and angiostatic factors, such as CXC chemokines play an important role in the pathogenesis of this process. On this basis, they represent potential therapeutic targets for the treatment of chronic inflammatory/fibroproliferative disorders associated with aberrant angiogenesis.

\section{Chemokine-induced angiogenesis in tumour models}

Angiogenesis is an essential feature of development and progression of cancers, and represents an intriguing, if as yet elusive, therapeutic target (93). CXC chemokine-mediated angiogenesis has been shown to play a critical role in growth of many cancers, including bronchogenic carcinoma, breast cancer, gastrointestinal malignancies, prostate carcinoma, melanoma, renal cell carcinoma, ovarian cancer, glioblastoma, and head and neck cancer (94-100).

CXCL1, CXCL2, and CXCL3 have all been found to be highly expressed in human melanoma, and when transfected into immortalized murine melanocytes that otherwise do not form tumours, they transformed the phenotype to one of anchorage-independent growth in vitro and the ability to form highly vascular tumours in vivo $(101,102)$. Furthermore, depletion of CXCL1, 2, or 3 in the hosts resulted in marked attenuation of tumour-associated angiogenesis and inhibition of tumour growth $(101,102)$.

Human pancreatic cancer cell lines also secrete the angiogenic chemokines CXCL1 and CXCL8 (103) with substantial heterogeneity in expression of these ligands between tumour lines (104). In comparing these lines using the corneal micropocket model, tumour-induced angiogenesis could be abrogated by blocking CXCR2 in one, but not another, cancer cell line (104), supporting the concept of redundancy of angiogenic ligands even within specific cancers. Similarly, in another gastrointestinal tract malignancy, colorectal cancer, PGE2 was found to induce in-vivo tumour growth by inducing expression of CXCL1 (105).

The progression of ovarian carcinoma is also dependent on successful angiogenesis. In one study of human ovarian carcinoma cell lines, in-vitro expression of CXCL8 by the lines correlated with tumour vascularity and tumour-induced mortality when implanted into the peritoneum of immunocompromised mice, whereas expression of VEGF correlated with ascites production only (106). In corroboration of this, another study found the angiogenic activity of ascites fluid from patients with ovarian cancer to correspond to its CXCL8 level (107).

CXCL8 also contributes to the angiogenic activity of NSCLC, and NSCLC cell lines that constitutively express CXCL8 display greater virulence and angiogenic activity in mice (25, 108). In a model of human NSCLC in SCID mice, tumour- derived CXCL8 directly correlated with tumourigenesis, and CXCL8 depletion resulted in reduced tumour angiogenesis associated with reduced tumour size and metastatic potential (109). Similarly, CXCL5 also mediates NSCLC-associated angiogenesis (110): Both in surgical specimens and in the SCID mouse model, CXCL5 expression was directly correlated with tumour angiogenesis (110). Moreover, when NSCLC tumour-bearing animals were depleted of CXCL5, both tumour growth and spontaneous metastases were markedly attenuated, but in- 
vivo and in-vitro proliferation of NSCLC cells was unaffected by the presence of CXCL5 (110). While a significant correlation of CXCL5 exists with tumour-derived angiogenesis, tumour growth, and metastases, CXCL5 depletion does not completely inhibit tumour growth (110), presumably reflecting a functional redundancy between angiogenic ligands. Overall, however, when all ELR+ CXC chemokines are evaluated in human NSCLC samples, it appears that their expression correlated with patient mortality $(111,112)$. As further evidence for this, in a lung cancer syngeneic tumour model system in CXCR2deficient, as compared to wildtype mice, cancers in CXCR2-deficient mice demonstrate reduced growth, increased tumour-associated necrosis, inhibited tumour-associated angiogenesis and metastatic potential (113). In a different model, spontaneously developing lung adenocarcinomas in mice with somatic activation of the oncogene KRAS were found to produce ELR+ CXC chemokines, and neutralization of CXCR2 in these animals inhibited the development of pre-malignant lesions and apoptosis of endothelial cells within the lesions (114). These in-vitro and in-vivo studies establish that CXCR2 is an important receptor that mediates ELR+ CXC chemokine-dependent angiogenic activity.

In patients with prostate cancer, serum CXCL8 levels are elevated and correlate with disease stage independent of the ratio of free-to-total prostate specific antigen (PSA) $(115,116)$. In a model of implantation of human prostate cancer into SCID mice, different prostate cancer cell lines were found to use different ELR+ CXC chemokine ligands as angiogenic mediators, with depletion of CXCL1 and nor CXCL8 inhibiting tumour growth and angiogenesis in some lines, and the converse in other lines (117). Thus, prostate cancer cell lines can utilize distinct CXC chemokines to mediate their tumourigenic potential.

Glioblastoma multiforme are highly aggressive brain tumours, associated with marked angiogenesis $(118,119)$. In a study of ING4, a candidate tumour suppressor gene, the gene was found to be down-regulated in human glioblastoma samples, and samples with lowest expression had greatest growth and angiogenesis when implanted into immunocompromised mice (118). The mechanism for this increased tumourigenicity was found to be CXCL8dependent, as inhibition of CXCL8 in vivo markedly reduced their tumour growth and tumour-associated angiogenesis (118). These findings link a tumour suppressor gene to function and control of the expression of angiogenic ELR+ CXC chemokines in human tumours.

The observation that CXCR3 and its ligands both inhibit angiogenesis and mediate Th1-type cell mediated immunity via recruitment of CXCR3-expressing T cells (120-124) has led to the concept of "immunoangiostasis" in cancer $(125,126)$. As an example of this, intratumoural injection of a recombinant CC chemokine, CCL21, in tumours induced regression via spatial generation of intratumour IFN- $\gamma$, consequent CXCR3 ligands, and influx of CXCR3-expressing CD4, CD8, natural killer, and dendritic cells into both the tumour and the draining lymph nodes, in addition to a reduction in angiogenesis $(127,128)$. Furthermore, depletion studies demonstrated that CXCL9, CXCL10, and IFN- $\gamma$ each attenuated the anti-tumour effects of CCL21 (128). These findings are similar to the previously reported study of IL-12-mediated regression of renal cell carcinoma in a murine model, where the anti-tumour effect of IL-12 was lost when CXCR3 ligands were depleted (129). More recently, the effectiveness of systemic IL-2 therapy in the mouse model of renal cell carcinoma was shown to be CXCR3-dependent, and resulted in up-regulation of CXCR3 on peripheral blood mononuclear cells but, surprisingly, down-regulation of CXCR3 ligands in the tumour (125). The effectiveness of this therapy was substantially enhanced when it was combined with over-expression of the CXCR3 ligand, CXCL9, in the tumour (125). Taken collectively, these findings support the notion that CXCR3 and its ligands contribute to anti-tumour defenses by two distinct and additive mechanisms, namely inhibition of angiogenesis and mediating direct anti-tumour immunity. 


\section{Therapeutic manipulation of chemokinemediated angiogenesis}

Chemokine-mediated angiogenesis and angiostasis have the potential to be utilized therapeutically, specially as adjunctive treatments in cancer and perhaps in fibroproliferative disorders. In this context, a neutralizing human anti-IL-8 mAb, shown to inhibit the effects of IL-8 in vitro and in preclinical models (130-132), had an acceptable safety profile in phase I trials but was abandoned when, in a phase II study of psoriasis, it did not meet its primary endpoint (133). Several compounds, currently in phase I and II trials, target the CXCR4-CXCL12 axis in various cancers (133), but as described above, this axis likely targets mechanisms other rather than angiogenesis. Interrupting the CCR2-CCL2 axis has the potential to interrupt angiogenesis but is likely to have a number of other complex effects, including inhibition of inflammatory leukocyte recruitment and augmenting Th-1 imunity; similarly targeting the CXCR3-ELR ${ }^{-}$CXC chemokine axis via systemic administration of IL-2 and intra-tumour administration of a ligand, as outlined above, may be effective in inhibiting angiogenesis and augmenting tumour rejection.

\section{Conclusion}

Although the function of chemokines was originally thought to be limited to recruitment of subpopulations of leukocytes, it has become clear that these cytokines display pleiotropic effects in other biological functions. These ligands appear to be important in the regulation of angiogenesis in inflammatory conditions, fibrosis, and malignancy. The findings summarized here support the notion that therapy directed at either inhibition of angiogenic or augmentation of angiostatic CC and CXC chemokines may be a novel approach in the treatment of a variety of such disorders.

\section{Acknowledgments}

Financial support: This work was supported by NIH grants HL73848 and an American Lung Association Career Investigator Award (Mehrad), AR055075 (Keane), and CA87879 and HL66027 (Strieter).

\section{References}

1. Belperio JA, Keane MP, Arenberg DA, et al. CXC chemokines in angiogenesis. J Leukoc Biol. 2000; 68:1-8. [PubMed: 10914483]

2. Strieter RM, Polverini PJ, Kunkel SL, et al. The functional role of the 'ELR' motif in CXC chemokine-mediated angiogenesis. J Biol Chem. 1995; 270:27348-27357. [PubMed: 7592998]

3. Addison CL, Daniel TO, Burdick MD, et al. The CXC chemokine receptor 2, CXCR2, is the putative receptor for ELR(+) CXC chemokine-induced angiogenic activity. J Immunol. 2000; 165:5269-5277. [PubMed: 11046061]

4. Murdoch C, Monk PN, Finn A. Cxc Chemokine receptor expression on human endothelial cells. Cytokine. 1999; 11:704-712. [PubMed: 10479407]

5. Salcedo R, Resau JH, Halverson D, et al. Differential expression and responsiveness of chemokine receptors (CXCR1-3) by human microvascular endothelial cells and umbilical vein endothelial cells. Faseb J. 2000; 14:2055-2064. [PubMed: 11023990]

6. Heidemann J, Ogawa H, Dwinell MB, et al. Angiogenic effects of interleukin 8 (CXCL8) in human intestinal microvascular endothelial cells are mediated by CXCR2. J Biol Chem. 2003; 278:85088515. [PubMed: 12496258]

7. Devalaraja RM, Nanney LB, Du J, et al. Delayed wound healing in CXCR2 knockout mice. J Invest Dermatol. 2000; 115:234-244. [PubMed: 10951241]

8. Balkwill F. The molecular and cellular biology of the chemokines. J Viral Hepat. 1998; 5:1-14. [PubMed: 9493511] 
9. Ehlert JE, Addison CA, Burdick MD, et al. Identification and partial characterization of a variant of human CXCR3 generated by posttranscriptional exon skipping. J Immunol. 2004; 173:6234-6240. [PubMed: 15528361]

10. Loetscher M, Loetscher P, Brass N, et al. Lymphocyte- specific chemokine receptor CXCR3: regulation, chemokine binding and gene localization. Eur J Immunol. 1998; 28:3696-3705. [PubMed: 9842912]

11. Luster AD, Cardiff RD, MacLean JA, et al. Delayed wound healing and disorganized neovascularization in transgenic mice expressing the IP-10 chemokine. Proc Assoc Am Physicians. 1998; 110:183-196. [PubMed: 9625525]

12. Rollins BJ. Chemokines. Blood. 1997; 90:909-928. [PubMed: 9242519]

13. Soto H, Wang W, Strieter RM, et al. The CC chemokine 6Ckine binds the CXC chemokine receptor CXCR3. Proc Natl Acad Sci USA. 1998; 95:8205-8210. [PubMed: 9653165]

14. Romagnani P, Annunziato F, Lasagni L, et al. Cell cycle-dependent expression of CXC chemokine receptor 3 by endothelial cells mediates angiostatic activity. J Clin Invest. 2001; 107:53-63. [PubMed: 11134180]

15. Lasagni L, Francalanci M, Annunziato F, et al. An alternatively spliced variant of CXCR3 mediates the inhibition of endothelial cell growth induced by IP-10, Mig, and I-TAC, and acts as functional receptor for platelet factor 4. J Exp Med. 2003; 197:1537-1549. [PubMed: 12782716]

16. Balabanian K, Lagane B, Infantino S, et al. The chemokine SDF-1/CXCL12 binds to and signals through the orphan receptor RDC1 in T lymphocytes. J Biol Chem. 2005; 280:35760-35766. [PubMed: 16107333]

17. Burns JM, Summers BC, Wang Y, et al. A novel chemokine receptor for SDF-1 and I-TAC involved in cell survival, cell adhesion, and tumor development. J Exp Med. 2006; 203:22012213. [PubMed: 16940167]

18. Yang J, Richmond A. The angiostatic activity of interferon- inducible protein-10/CXCL10 in human melanoma depends on binding to CXCR3 but not to glycosaminoglycan. Mol Ther. 2004; 9:846-855. [PubMed: 15194051]

19. Phillips RJ, Burdick MD, Lutz M, et al. The stromal derived factor-1/CXCL12-CXC chemokine receptor 4 biological axis in non-small cell lung cancer metastases. Am J Respir Crit Care Med. 2003; 167:1676-1686. [PubMed: 12626353]

20. Bachelder RE, Wendt MA, Mercurio AM. Vascular endothelial growth factor promotes breast carcinoma invasion in an autocrine manner by regulating the chemokine receptor CXCR4. Cancer Res. 2002; 62:7203-7206. [PubMed: 12499259]

21. Kijowski J, Baj-Krzyworzeka M, Majka M, et al. The SDF-1-CXCR4 axis stimulates VEGF secretion and activates integrins but does not affect proliferation and survival in lymphohematopoietic cells. Stem Cells. 2001; 19:453-466. [PubMed: 11553854]

22. Salcedo R, Wasserman K, Young HA, et al. Vascular endothelial growth factor and basic fibroblast growth factor induce expression of CXCR4 on human endothelial cells: In vivo neovascularization induced by stromal-derived factor-1alpha. Am J Pathol. 1999; 154:1125-1135. [PubMed: 10233851]

23. Muller A, Homey B, Soto H, et al. Involvement of chemokine receptors in breast cancer metastasis. Nature. 2001; 410:50-56. [PubMed: 11242036]

24. Schrader AJ, Lechner O, Templin M, et al. CXCR4/CXCL12 expression and signalling in kidney cancer. Br J Cancer. 2002; 86:1250-1256. [PubMed: 11953881]

25. Smith DR, Polverini PJ, Kunkel SL, et al. IL-8 mediated angiogenesis in human bronchogenic carcinoma. J Exp Med. 1994; 179:1409-1415. [PubMed: 7513008]

26. Arenberg DA, Kunkel SL, Polverini PJ, et al. Inhibition of interleukin-8 reduces tumorigenesis of human non-small cell lung cancer in SCID mice. J Clin Invest. 1996; 97:2792-2802. [PubMed: 8675690]

27. Arenberg DA, Kunkel SL, Polverini PJ, et al. Interferon- $\gamma$-inducible protein 10 (IP-10) is an angiostatic factor that inhibits human non-small cell lung cancer (NSCLC) tumorigenesis and spontaneous metastases. J Exp Med. 1996; 184:981-992. [PubMed: 9064358] 
28. Arenberg DA, Zlotnick A, Strom SR, et al. The murine CC chemokine, 6C-kine, inhibits tumor growth and angiogenesis in a human lung cancer SCID mouse model. Cancer Immunol Immunother. 2001; 49:587-592. [PubMed: 11225989]

29. Salcedo R, Young HA, Ponce ML, et al. Eotaxin (CCL11) induces in vivo angiogenic responses by human CCR3+ endothelial cells. J Immunol. 2001; 166:7571-7578. [PubMed: 11390513]

30. Strasly M, Doronzo G, Capello P, et al. CCL16 activates an angiogenic program in vascular endothelial cells. Blood. 2004; 103:40-49. [PubMed: 12958070]

31. Galvez BG, Genis L, Matias-Roman S, et al. Membrane type 1-matrix metalloproteinase is regulated by chemokines monocyte-chemoattractant protein-1/ccl 2 and interleukin-8/CXCL8 in endothelial cells during angiogenesis. J Biol Chem. 2005; 280:1292-1298. [PubMed: 15516694]

32. Weber KS, Nelson PJ, Grone HJ, et al. Expression of CCR2 by endothelial cells: implications for MCP-1 mediated wound injury repair and in vivo inflammatory activation of endothelium. Arterioscler Thromb Vasc Biol. 1999; 19:2085-2093. [PubMed: 10479649]

33. Goede V, Brogelli L, Ziche M, et al. Induction of inflammatory angiogenesis by monocyte chemoattractant protein-1. Int J Cancer. 1999; 82:765-770. [PubMed: 10417778]

34. Salcedo R, Ponce ML, Young HA, et al. Human endothelial cells express CCR 2 and respond to MCP-1: direct role of MCP-1 in angiogenesis and tumor progression. Blood. 2000; 96:34-40. [PubMed: 10891427]

35. Barcelos LS, Talvani A, Teixeira AS, et al. Production and in vivo effects of chemokines CXCL13/KC and CCL2/JE in a model of inflammatory angiogenesis in mice. Inflamm Res. 2004; 53:576-584. [PubMed: 15597153]

36. Stamatovic SM, Keep RF, Mostarica-Stojkovic M, et al. CCL2 regulates angiogenesis via activation of Ets-1 transcription factor. J Immunol. 2006; 177:2651-2661. [PubMed: 16888027]

37. Burger M, Burger JA, Hoch RC, et al. Point mutation causing constitutive signaling of CXCR2 leads to transforming activity similar to Kaposi's sarcoma herpesvirus-G protein- coupled receptor. J Immunol. 1999; 163:2017-2022. [PubMed: 10438939]

38. Gershengorn MC, Geras-Raaka E, Varma A, et al. Chemokines activate Kaposi's sarcomaassociated herpesvirus $\mathrm{G}$ protein- coupled receptor in mammalian cells in culture [see comments]. J Clin Invest. 1998; 102:1469-1472. [PubMed: 9788958]

39. Arvanitakis L, Geras-Raaka E, Varma A, et al. Human herpesvirus KSHV encodes a constitutively active G-protein- coupled receptor linked to cell proliferation [see comments]. Nature. 1997; 385:347-350. [PubMed: 9002520]

40. Bais C, Santomasso B, Coso O, et al. G-proteincoupled receptor of Kaposi's sarcoma-associated herpesvirus is a viral oncogene and angiogenesis activator [see comments] [published erratum in Nature 1998; 392: 210]. Nature. 1998; 391:86-89. [PubMed: 9422510]

41. Geras-Raaka E, Arvanitakis L, Bais C, et al. Inhibition of constitutive signaling of Kaposi's sarcoma-associated herpesvirus $\mathrm{G}$ protein-coupled receptor by protein kinases in mammalian cells in culture. J Exp Med. 1998; 187:801-806. [PubMed: 9480990]

42. Guo HG, Sadowska M, Reid W, et al. Kaposi's sarcoma- like tumors in a human herpesvirus 8 ORF74 transgenic mouse. J Virol. 2003; 77:2631-2639. [PubMed: 12552002]

43. Yang TY, Chen SC, Leach MW, et al. Transgenic expression of the chemokine receptor encoded by human herpesvirus 8 induces an angioproliferative disease resembling Kaposi's sarcoma [see comments]. J Exp Med. 2000; 191:445-454. [PubMed: 10662790]

44. Maussang D, Verzij1 D, van Walsum M, et al. Human cytomegalovirus-encoded chemokine receptor US28 promotes tumorigenesis. Proc Natl Acad Sci USA. 2006; 103:13068-13073. [PubMed: 16924106]

45. Addison CL, Belperio JA, Burdick MD, et al. Overexpression of the duffy antigen receptor for chemokines (DARC) by NSCLC tumor cells results in increased tumor necrosis. BMC Cancer. 2004; 4:28. [PubMed: 15214968]

46. Du J, Luan J, Liu H, et al. Potential role for Duffy antigen chemokine-binding protein in angiogenesis and maintenance of homeostasis in response to stress. J Leukoc Biol. 2002; 71:141153. [PubMed: 11781390]

47. Shen H, Schuster R, Stringer KF, et al. The Duffy antigen/receptor for chemokines (DARC) regulates prostate tumor growth. Faseb J. 2006; 20:59-64. [PubMed: 16394268] 
48. Wang J, Ou ZL, Hou YF, et al. Enhanced expression of Duffy antigen receptor for chemokines by breast cancer cells attenuates growth and metastasis potential. Oncogene. 2006; 25:7201-7211. [PubMed: 16785997]

49. Maione TE, Gray GS, Petro J, et al. Inhibition of angiogenesis by recombinant human platelet factor-4. Science. 1990; 247:77-79. [PubMed: 1688470]

50. Bikfalvi A. Platelet factor 4: an inhibitor of angiogenesis. Semin Thromb Hemost. 2004; 30:379_ 385. [PubMed: 15282661]

51. Gentilini G, Kirschbaum NE, Augustine JA, et al. Inhibition of human umbilical vein endothelial cell proliferation by the CXC chemokine, platelet factor 4 (PF4), is associated with impaired downregulation of p21(Cip1/WAF1). Blood. 1999; 93:25-33. [PubMed: 9864142]

52. Sulpice E, Bryckaert M, Lacour J, et al. Platelet factor 4 inhibits FGF2-induced endothelial cell proliferation via the extracellular signal-regulated kinase pathway but not by the phosphatidylinositol 3-kinase pathway. Blood. 2002; 100:3087-3094. [PubMed: 12384403]

53. Perollet C, Han ZC, Savona C, et al. Platelet factor 4 modulates fibroblast growth factor 2 (FGF-2) activity and inhibits FGF-2 dimerization. Blood. 1998; 91:3289-3299. [PubMed: 9558385]

54. Bikfalvi A, Gimenez-Gallego G. The control of angiogenesis and tumor invasion by platelet factor-4 and platelet factor-4-derived molecules. Semin Thromb Hemost. 2004; 30:137-144. [PubMed: 15034805]

55. Dudek AZ, Nesmelova I, Mayo K, et al. Platelet factor 4 promotes adhesion of hematopoietic progeni- tor cells and binds IL-8: novel mechanisms for modulation of hematopoiesis. Blood. 2003; 101:4687-4694. [PubMed: 12586630]

56. Eisman R, Surrey S, Ramachandran B, et al. Structural and functional comparison of the genes for human platelet factor 4 and PF4alt. Blood. 1990; 76:336-344. [PubMed: 1695112]

57. Green CJ, Charles RS, Edwards BF, et al. Identification and characterization of PF4varl, a human gene variant of platelet factor 4. Mol Cell Biol. 1989; 9:1445-1451. [PubMed: 2725510]

58. Lasagni L, Grepin R, Mazzinghi B, et al. PF-4/CXCL4 and CXCL4L1 exhibit distinct subcellular localization and a differentially regulated mechanism of secretion. Blood. 2007 epub ahead of print.

59. Struyf S, Burdick MD, Proost P, et al. Platelets release CXCL4L1, a nonallelic variant of the chemokine platelet factor-4/CXCL4 and potent inhibitor of angiogenesis. Circ Res. 2004; 95:855857. [PubMed: 15459074]

60. Hromas R, Broxmeyer HE, Kim C, et al. Cloning of BRAK, a novel divergent CXC chemokine preferentially expressed in normal versus malignant cells. Biochem Biophys Res Commun. 1999; 255:703-706. [PubMed: 10049774]

61. Sleeman MA, Fraser JK, Murison JG, et al. B cell- and monocyte-activating chemokine (BMAC), a novel non-ELR alpha-chemokine. Int Immunol. 2000; 12:677-689. [PubMed: 10784614]

62. Frederick MJ, Henderson Y, Xu X, et al. In vivo expression of the novel CXC chemokine BRAK in normal and cancerous human tissue. Am J Pathol. 2000; 156:1937-1950. [PubMed: 10854217]

63. Shellenberger TD, Wang M, Gujrati M, et al. BRAK/CXCL14 is a potent inhibitor of angiogenesis and is a chemotactic factor for immature dendritic cells. Cancer Res. 2004; 64:8262-8270. [PubMed: 15548693]

64. Schwarze SR, Luo J, Isaacs WB, et al. Modulation of CXCL14 (BRAK) expression in prostate cancer. Prostate. 2005; 13:13.

65. Koch AE, Volin MV, Woods JM, et al. Regulation of angiogenesis by the C-X-C chemokines interleukin-8 and epithelial neutrophil activating peptide 78 in the rheumatoid joint. Arthritis Rheum. 2001; 44:31-40. [PubMed: 11212173]

66. Nickoloff BJ, Mitra RS, Varani J, et al. Aberrant production of interleukin-8 and thrombospondin-1 by psoriatic keratinocytes mediates angiogenesis. Am J Pathol. 1994; 144:820 828. [PubMed: 7512793]

67. Fowler S, Berberian PA, Shio H, et al. Characterization of cell populations isolated from aortas of rhesus monkeys with experimental atherosclerosis. Circ Res. 1980; 46:520-530. [PubMed: 6244120] 
68. Joris I, Zand T, Nunnari JJ, et al. Studies on the pathogenesis of atherosclerosis. I. Adhesion and emigration of mononuclear cells in the aorta of hypercholesterolemic rats. Am J Pathol. 1983; 113:341-358. [PubMed: 6650664]

69. Munro JM, Cotran RS. The pathogenesis of atherosclerosis: atherogenesis and inflammation. Lab Invest. 1988; 58:249-261. [PubMed: 3279259]

70. Chen $\mathrm{CH}$, Walterscheid JP. Plaque angiogenesis versus compensatory arteriogenesis in atherosclerosis. Circ Res. 2006; 99:787-789. [PubMed: 17038645]

71. Khurana R, Simons M, Martin JF, et al. Role of angiogenesis in cardiovascular disease: a critical appraisal. Circulation. 2005; 112:1813-1824. [PubMed: 16172288]

72. Winter PM, Morawski AM, Caruthers SD, et al. Molecular imaging of angiogenesis in early-stage atherosclerosis with alpha(v)beta3-integrin-targeted nanoparticles. Circulation. 2003; 108:2270 2274. [PubMed: 14557370]

73. Simonini A, Moscucci M, Muller DW, et al. IL-8 is an angiogenic factor in human coronary atherectomy tissue. Circulation. 2000; 101:1519-1526. [PubMed: 10747344]

74. Damas JK, Eiken HG, Oie E, et al. Myocardial expression of CC- and CXC-chemokines and their receptors in human end-stage heart failure. Cardiovasc Res. 2000; 47:778-787. [PubMed: 10974226]

75. Lakshminarayanan V, Lewallen M, Frangogiannis NG, et al. Reactive oxygen intermediates induce monocyte chemotactic protein-1 in vascular endothelium after brief ischemia. Am J Pathol. 2001; 159:1301-1311. [PubMed: 11583958]

76. Dewald O, Zymek P, Winkelmann K, et al. CCL2/Monocyte Chemoattractant Protein-1 regulates inflammatory responses critical to healing myocardial infarcts. Circ Res. 2005; 96:881-889. [PubMed: 15774854]

77. Heil M, Ziegelhoeffer T, Wagner S, et al. Collateral artery growth (arteriogenesis) after experimental arterial occlusion is impaired in mice lacking CC-chemokine receptor-2. Circ Res. 2004; 94:671-677. [PubMed: 14963007]

78. Charan NB, Baile EM, Pare PD. Bronchial vascular congestion and angiogenesis. Eur Respir J. 1997; 10:1173-1180. [PubMed: 9163664]

79. Charan NB, Carvalho P. Angiogenesis in bronchial circulatory system after unilateral pulmonary artery obstruction. J Appl Physiol. 1997; 82:284-291. [PubMed: 9029228]

80. Michel RP, Hakim TS. Increased resistance in postobstructive pulmonary vasculopathy: structurefunction relationships. J Appl Physiol. 1991; 71:601-610. [PubMed: 1938734]

81. Michel RP, Hakim TS, Petsikas D. Segmental vascular resistance in postobstructive pulmonary vasculopathy. J Appl Physiol. 1990; 69:1022-32. [PubMed: 2246149]

82. Srisuma S, Biswal SS, Mitzner WA, et al. Identification of genes promoting angiogenesis in mouse lung by transcriptional profiling. Am J Respir Cell Mol Biol. 2003; 29:172-179. [PubMed: 12600816]

83. Mitzner W, Lee W, Georgakopoulos D, et al. Angiogenesis in the mouse lung. Am J Pathol. 2000; 157:93-101. [PubMed: 10880380]

84. Turner-Warwick M. Precapillary systemic-pulmonary anastomoses. Thorax. 1963; 18:225-237. [PubMed: 14064617]

85. Peao MND, Aguas AP, DeSa CM, et al. Neoformation of blood vessels in association with rat lung fibrosis induced by bleomycin. Anat Rec. 1994; 238:57-67. [PubMed: 7509580]

86. Keane MP, Arenberg DA, Lynch JPr, et al. The CXC chemokines, IL-8 and IP-10, regulate angiogenic activity in idiopathic pulmonary fibrosis. J Immunol. 1997; 159:1437-1443. [PubMed: 9233641]

87. Keane MP, Belperio JA, Arenberg DA, et al. IFN-gamma-inducible protein-10 attenuates bleomycin-induced pulmonary fibrosis via inhibition of angiogenesis. J Immunol. 1999; 163:5686-5692. [PubMed: 10553099]

88. Keane MP, Belperio JA, Moore TA, et al. Neutralization of the CXC chemokine, macrophage inflammatory protein-2, attenuates bleomycin-induced pulmonary fibrosis. J Immunol. 1999; 162:5511-5518. [PubMed: 10228032] 
89. Burdick MD, Murray LA, Keane MP, et al. CXCL11 attenuates bleomycin-induced pulmonary fibrosis via inhibition of vascular remodeling. Am J Respir Crit Care Med. 2005; 171:261-268. [PubMed: 15502109]

90. Wilkes DS, Egan TM, Reynolds HY. Lung transplantation: opportunities for research and clinical advancement. Am J Respir Crit Care Med. 2005; 172:944-955. [PubMed: 16020804]

91. Belperio JA, Keane MP, Burdick MD, et al. Role of CXCR2/CXCR2 ligands in vascular remodeling during bronchiolitis obliterans syndrome. J Clin Invest. 2005; 115:1150-1162. [PubMed: 15864347]

92. Keane MP, Donnelly SC, Belperio JA, et al. Imbalance in the expression of CXC chemokines correlates with bronchoalveolar lavage fluid angiogenic activity and procollagen levels in acute respiratory distress syndrome. J Immunol. 2002; 169:6515-6521. [PubMed: 12444162]

93. Strieter RM. Masters of angiogenesis. Nat Med. 2005; 11:925-927. [PubMed: 16145572]

94. Miller LJ, Kurtzman SH, Wang Y, et al. Expression of interleukin-8 receptors on tumor cells and vascular endothelial cells in human breast cancer tissue. Anticancer Res. 1998; 18:77-81. [PubMed: 9568059]

95. Richards BL, Eisma RJ, Spiro JD, et al. Coexpression of interleukin-8 receptors in head and neck squamous cell carcinoma. Am J Surg. 1997; 174:507-512. [PubMed: 9374226]

96. Kitadai Y, Haruma K, Sumii K, et al. Expression of interleukin-8 correlates with vascularity in human gastric carcinomas. Am J Pathol. 1998; 152:93-100. [PubMed: 9422527]

97. Singh RK, Gutman M, Radinsky R, et al. Expression of interleukin 8 correlates with the metastatic potential of human melanoma cells in nude mice. Cancer Res. 1994; 54:3242-3247. [PubMed: 8205546]

98. Cohen RF, Contrino J, Spiro JD, et al. Interleukin-8 expression by head and neck squamous cell carcinoma. Arch Otolaryngol Head Neck Surg. 1995; 121:202-209. [PubMed: 7840929]

99. Chen Z, Malhotra PS, Thomas GR, et al. Expression of proinflammatory and proangiogenic cytokines in patients with head and neck cancer. Clin Cancer Res. 1999; 5:1369-1379. [PubMed: 10389921]

100. Mestas J, Burdick MD, Reckamp K, et al. The role of CXCR2/CXCR2 ligand biological axis in renal cell carcinoma. J Immunol. 2005; 175:5351-5357. [PubMed: 16210641]

101. Luan J, Shattuck-Brandt R, Haghnegahdar H, et al. Mechanism and biological significance of constitutive expression of MGSA/GRO chemokines in malignant melanoma tumor progression. J Leukoc Biol. 1997; 62:588-597. [PubMed: 9365113]

102. Owen JD, Strieter R, Burdick M, et al. Enhanced tumor-forming capacity for immortalized melanocytes expressing melanoma growth stimulatory activity/growth-regulated cytokine beta and gamma proteins. Int J Cancer. 1997; 73:94-103. [PubMed: 9334815]

103. Takamori H, Oades ZG, Hoch OC, et al. Autocrine growth effect of IL-8 and GROalpha on a human pancreatic cancer cell line, Capan-1. Pancreas. 2000; 21:52-56. [PubMed: 10881932]

104. Wente MN, Keane MP, Burdick MD, et al. Block-ade of the chemokine receptor CXCR2 inhibits pancreatic cancer cell-induced angiogenesis. Cancer Lett. 2006; 241:221-227. [PubMed: 16458421]

105. Wang D, Wang H, Brown J, et al. CXCL1 induced by prostaglandin E2 promotes angiogenesis in colorectal cancer. J Exp Med. 2006; 203:941-951. [PubMed: 16567391]

106. Yoneda J, Kuniyasu H, Crispens MA, et al. Expression of angiogenesis-related genes and progression of human ovarian carcinomas in nude mice. J Natl Cancer Inst. 1998; 90:447-454. [PubMed: 9521169]

107. Gawrychowski K, Skopinska-Rozewska E, Barcz E, et al. Angiogenic activity and interleukin-8 content of human ovarian cancer ascites. Eur J Gynaecol Oncol. 1998; 19:262-264. [PubMed: 9641227]

108. Yatsunami J, Tsuruta N, Ogata K, et al. Interleukin- 8 participates in angiogenesis in non-small cell, but not small cell carcinoma of the lung. Cancer Lett. 1997; 120:101-108. [PubMed: 9570392]

109. Arenberg DA, Kunkel SL, Burdick MD, et al. Treatment with anti-IL-8 inhibits non-small cell lung cancer tumor growth (Meeting abstract). J Investig Med. 1995; 43 (Suppl 3):479A. 
110. Arenberg DA, Keane MP, DiGiovine B, et al. Epithelial-neutrophil activating peptide (ENA-78) is an important angiogenic factor in non-small cell lung cancer. J Clin Invest. 1998; 102:465472. [PubMed: 9691082]

111. White ES, Flaherty KR, Carskadon S, et al. Macrophage migration inhibitory factor and CXC chemokine expression in non-small cell lung cancer: role in angiogenesis and prognosis. Clin Cancer Res. 2003; 9:853-860. [PubMed: 12576459]

112. Chen JJ, Yao PL, Yuan A, et al. Up-regulation of tumor interleukin-8 expression by infiltrating macro-phages: its correlation with tumor angiogenesis and patient survival in non-small cell lung cancer. Clin Cancer Res. 2003; 9:729-737. [PubMed: 12576442]

113. Keane MP, Belperio JA, Xue YY, et al. Depletion of CXCR2 inhibits tumor growth and angiogenesis in a murine model of lung cancer. J Immunol. 2004; 172:2853-2860. [PubMed: 14978086]

114. Wislez M, Fujimoto N, Izzo JG, et al. High expression of ligands for chemokine receptor CXCR2 in alveolar epithelial neoplasia induced by oncogenic kras. Cancer Res. 2006; 66:4198-4207. [PubMed: 16618742]

115. Fregene TA, Khanuja PS, Noto AC, et al. Tumor-associated angiogenesis in prostate cancer. Anticancer Res. 1993; 13:2377-2381. [PubMed: 7510938]

116. Kim SJ, Uehara H, Karashima T, et al. Expression of interleukin-8 correlates with angiogenesis, tumorigenicity, and metastasis of human prostate cancer cells implanted orthotopically in nude mice. Neoplasia. 2001; 3:33-42. [PubMed: 11326314]

117. Moore BB, Arenberg DA, Stoy K, et al. Distinct CXC chemokines mediate tumorigenicity of prostate cancer cells. Am J Pathol. 1999; 154:1503-1512. [PubMed: 10329603]

118. Garkavtsev I, Kozin SV, Chernova O, et al. The candidate tumour suppressor protein ING4 regulates brain tumour growth and angiogenesis. Nature. 2004; 428:328-332. [PubMed: 15029197]

119. Charalambous C, Chen TC, Hofman FM. Characteristics of tumor-associated endothelial cells derived from glioblastoma multiforme. Neurosurg Focus. 2006; 20:E22. [PubMed: 16709028]

120. Loetscher M, Gerber B, Loetscher P, et al. Chemokine receptor specific for IP10 and mig: structure, function, and expression in activated T-lymphocytes. J Exp Med. 1996; 184:963-996. [PubMed: 9064356]

121. Moser M. Regulation of Th1/Th2 development by antigen-presenting cells in vivo. Immunobiology. 2001; 204:551-557. [PubMed: 11846218]

122. Rabin RL, Park MK, Liao F, et al. Chemokine receptor responses on T cells are achieved through regulation of both receptor expression and signaling. J Immunol. 1999; 162:3840-3850. [PubMed: 10201901]

123. Luster AD. Chemokines--chemotactic cytokines that mediate inflammation. N Engl J Med. 1998; 338:436-445. [PubMed: 9459648]

124. Qin S, Rottman JB, Myers P, et al. The chemokine receptors CXCR3 and CCR5 mark subsets of T cells associated with certain inflammatory reactions. J Clin Invest. 1998; 101:746-754. [PubMed: 9466968]

125. Pan J, Burdick MD, Belperio JA, et al. CXCR3/CXCR3 ligand biological axis impairs RENCA tumor growth by a mechanism of immunoangiostasis. J Immunol. 2006; 176:1456-1464. [PubMed: 16424173]

126. Strieter RM, Belperio JA, Burdick MD, et al. CXC chemokines: angiogenesis, immunoangiostasis, and metastases in lung cancer. Ann NY Acad Sci. 2004; 1028:351-360. [PubMed: 15650260]

127. Sharma S, Stolina M, Luo J, et al. Secondary lymphoid tissue chemokine mediates T celldependent antitumor responses in vivo. J Immunol. 2000; 164:4558-4563. [PubMed: 10779757]

128. Sharma S, Yang SC, Hillinger S, et al. SLC/CCL21-mediated anti-tumor responses require IFNgamma, MIG/CXCL9 and IP-10/CXCL10. Mol Cancer. 2003; 2:22. [PubMed: 12740040]

129. Tannenbaum CS, Tubbs R, Armstrong D, et al. The CXC chemokines IP-10 and Mig are necessary for IL-12-mediated regression of the mouse RENCA tumor. J Immunol. 1998; 161:927-932. [PubMed: 9670971] 
130. Huang S, Mills L, Mian B, et al. Fully humanized neutralizing antibodies to interleukin-8 (ABXIL8) inhibit angiogenesis, tumor growth, and metastasis of human melanoma. Am J Pathol. 2002; 161:125-134. [PubMed: 12107097]

131. Mian BM, Dinney CP, Bermejo CE, et al. Fully human anti-interleukin 8 antibody inhibits tumor growth in orthotopic bladder cancer xenografts via down-regulation of matrix metalloproteases and nuclear factor-kappaB. Clin Cancer Res. 2003; 9:3167-3175. [PubMed: 12912969]

132. Yang XD, Corvalan JR, Wang P, et al. Fully human anti-interleukin-8 monoclonal antibodies: potential therapeutics for the treatment of inflammatory disease states. J Leukoc Biol. 1999; 66:401-410. [PubMed: 10496309]

133. Yan L, Anderson GM, DeWitte M, et al. Therapeutic potential of cytokine and chemokine antagonists in cancer therapy. Eur J Cancer. 2006; 42:793-802. [PubMed: 16524718]

134. Chemokine/chemokine receptor nomenclature. Cytokine. 2003; 21:48-49. [PubMed: 12668160] 
Table 1

Chemokine ligands and receptors involved in angiogenesis

Modified from (134).

\begin{tabular}{|l|l|l|l|}
\hline Systematic name & Human ligand & Mouse ligand & Receptor \\
\hline Angiogenic & Gro-a & KC & CXCR2 \\
\hline CXCL1 & Gro- $\beta$ & MIP-2 & CXCR2 \\
\hline CXCL2 & Gro- $\gamma$ & MIP-2 & CXCR2 \\
\hline CXCL3 & ENA-78 & LIX & CXCR2 \\
\hline CXCL5 & GCP-2 & - & CXCR2 \\
\hline CXCL6 & NAP-2 & - & CXCR2 \\
\hline CXCL7 & IL-8 & - & CXCR2 \\
\hline CXCL8 & MCP-1 & JE & CCR2 \\
\hline CCL2 & & & \\
\hline Angiostatic & PF-4 & PF-4 & CXCR3B, \\
\hline CXCL4 & Mig & Mig & CXCR3B \\
\hline CXCL9 & IP-10 & IP-10 & CXCR3B \\
\hline CXCL10 & I-TAC & I-TAC & CXCR3B \\
\hline CXCL11 & SDF-1 & SDF-1 & CXCR4 \\
\hline CXCL12 & BRAK & BRAK & $?$ \\
\hline CXCL14 & & \\
\hline
\end{tabular}

* additional receptors may be involved (see text); ?, undefined receptor. 